_a debate El futuro de la conservación-restauración de bienes culturales | coordina Pilar Aguilar Solves

\title{
Redefiniendo la labor del conservador-restaurador
}

\author{
Gema Grueso Otalo | Departamento de Restauración, Museo Nacional Centro de Arte Reina Sofía
}

URL de la contribución <www.iaph.es/revistaph/index.php/revistaph/article/view/3538>

El título del debate es esperanzador porque presupone algo que no tantos profesionales tienen claro hoy en día: que hay un futuro. No pocos restauradores miran con preocupación el suyo propio y capean como pueden el temporal de la crisis que afecta directamente al gasto estatal y, por ende, a la inversión del mismo en las intervenciones en patrimonio.

La introducción al debate parece un buen punto de partida y expone las cuestiones básicas que atañen al desarrollo de un corpus profesional capaz de generar su propio trabajo y de construir un campo de conocimiento riguroso que pueda evolucionar y conseguir reconocimiento y prestigio público.

El texto comienza con una definición de la profesión. La cuestión semántica no debe menospreciarse en absoluto porque el mundo y el conocimiento se construyen con palabras. Apropiarnos de un término que nos nombre, nos explique y nos diferencie debería constituirse en un grupo de trabajo específico. Podríamos tomar ejemplo en esto de los conservadores: la RAE en el artículo enmendado en línea que es avance de la vigésima tercera edición tiene en la entrada conservador, ra. en la 4. ${ }^{a}$ acepción "En algunas instituciones, persona que cuida de sus fondos, documentos e intereses. El conservador del Museo del Prado". Deberíamos preguntarnos si restaurador, o la acepción que debemos imbuir en restaurador, cumple con precisión el cometido de designar nuestra actividad profesional en la actualidad.

Pero no me quiero extender más en este tema tangencial. Hablábamos de futuro.

Hay muchas ideas-fuerza expresadas en la introducción del tema que copan el centro de la diana, a mi parecer, de la cuestión del futuro de la profesión.

La redefinición de nuestras tareas, la comunicación y el trabajo directo con los grupos sociales a los que afecta nuestra labor, el equipo transdisciplinar que nos permite llevar más allá la intervención añadiendo valor al sitio/ objeto y pensando en proyectos que hagan sostenible el uso y mantenimiento del sitio/objeto. Estas claves que nos convertirán en agentes culturales y no en meros depositarios del milagro de la recuperación de la ruina, son los que apuntalan el futuro más deseable.

El futuro, tal como lo veo, no pasa por excluir a unos pocos (o a unos muchos tal como están planteadas las preguntas que deberían encauzar este debate). Tampoco pasa por establecer jerarquías que limiten las funciones de los pocos elegidos. Precisamente los equipos transdisciplinares (y esto debe incluir profesionales de otras disciplinas como su propio nombre indica) suelen ser horizontales y enriquecerse en los puntos de contacto que aparecen entre diferentes bagajes formativos y de experiencia cuando persiguen un objetivo común.

Si queremos mejorar la situación de nuestro cuerpo profesional debemos empezar por las cuestiones en las que podemos influir de manera directa. ¿O acaso pensamos que nuestro peso social, político, profesional o económico es suficiente para influir en la legislación o en la oferta formativa oficial?

Desde luego, todas las soluciones y planteamientos que sugieren las preguntas planteadas para el debate son de sentido común. Pero probablemente no seamos laúnica disciplina con superávit de oferta formativa, ni con incongruencias e indeterminaciones a la hora de establecer criterios para el acceso a puestos o becas en la administración.

El punto de partida sería el aglutinar a cualquier profesional cuya labor tenga parte en el proceso de recuperación, puesta en valor, mantenimiento, difusión o uso del patrimonio histórico/artístico en este país. 
a debate El futuro de la conservación-restauración de bienes culturales | coordina Pilar Aguilar Solves

Si lo que se desea es que deje de haber ecce homos de borja deberíamos facilitarle a la sociedad en su conjunto dónde, cómo y a quién dirigirse en busca de profesionales, materiales y/o consejo cuando se desea emprender un proyecto de intervención.

Si queremos normalizar y desarrollar estándares profesionales habrá que determinarlos primero y acostumbrar a la sociedad a ese mínimo de resultados a continuación.

Los estándares siempre se consensúan para que su adopción sea lo más generalizada posible, por eso además de estándares de iure existen innumerables estándares de facto.

Para conseguir el peso suficiente a todos los niveles, para que nuestras reclamaciones sean escuchadas, tenemos que convertirnos en agentes culturales proactivos. Trabajemos en estos equipos transdisciplinares que generen y se conviertan en generadores de valor a partir de intervenciones en bienes culturales. Comuniquémonos directamente con los grupos sociales a los que afectan nuestros proyectos, busquemos financiación en quienes sean potenciales beneficiarios del resultado de nuestra intervención. Conectando la intervención con el resto de disciplinas que forman el ciclo vital de un bien cultural podremos hacer sostenible la conservación de ese bien.

Una vez generemos riqueza en nuestro propio sector, el reconocimiento llegará con la difusión. Tenemos que intentar salir de nuestros círculos; el mundo de la conservación-restauración es muy pequeño hoy en día en Españay es tremendamente desconocido. Investiguemos canales de divulgación efectivos.

Por último, para que la conservación-restauración avance como disciplina necesitamos rigor. Sólo encima del conocimiento previo se puede construir más conocimiento, así que la necesidad básica es compartir la información. La era digital facilita en gran medida la distribución y el procesamiento de esta.
En resumen, el futuro de la conservación-restauración pasa por:

> La redefinición de la profesión.

> La conexión con otras disciplinas.

$>$ El trabajo proactivo en equipo.

> La divulgación y la información.

$>$ El establecimiento consensuado de estándares en la praxis.

$>$ Un repositorio de conocimiento accesible y reutilizable.

Por último, en las preguntas propuestas también se mencionan las asociaciones y los colegios.

El colegiarse me parece una barrera ante todo económica y que tampoco resuelve gran cosa mientras la sociedad siga considerando que alguien que pinta cosas agradables es capaz de restaurar una pintura.

Las asociaciones deberían poder ofrecer a sus asociados herramientas para el desarrollo y el ejercicio de su profesión, promover proyectos, abrir canales de comunicación directa con la sociedad, recopilar y compartir información sobre teoría y práctica y aglutinar a todo aquel que tenga algo que aportar al campo. Son imprescindibles si queremos avanzar como conjunto y la base para llegar a tener el peso para que se oigan nuestras demandas. 